\title{
Scardovia Wiggsiae and the Other Microorganisms in Severe Early Childhood Caries
}

\author{
Unsal G ${ }^{*}$, Topcuoglu $\mathrm{N}^{2}$, Ulukapi $\mathrm{I}^{3}$, Kulekci $\mathrm{G}^{2}$, and Aktoren $\mathrm{O}^{1}$ \\ ${ }^{1}$ Istanbul University, Faculty of Dentistry, Department of Pediatric Dentistry, Istanbul, Turkey \\ ${ }^{2}$ Istanbul University, Faculty of Dentistry, Department of Oral Microbiology, Istanbul, Turkey \\ ${ }^{3}$ Okan University, Faculty of Dentistry, Department of Pediatric Dentistry, Istanbul, Turkey
}

*Corresponding author: Unsal G, Istanbul University, Faculty of Dentistry, Department of Pediatric Dentistry, 35063 Fatih/ÇAPA, Istanbul, Turkey, Tel: +90 5065168355, E-mail: gulcansahinunsal@gmail.com

Citation: Unsal G, Topcuoglu N, Ulukapi I, Kulekci G, Aktoren O (2017) Scardovia Wiggsiae and the Other Microorganisms in Severe Early Childhood Caries. J Dent Oral Care Med 3(3): 302

Received Date: November 10, 2017 Accepted Date: December 27, 2017 Published Date: December 29, 2017

\begin{abstract}
Purpose: Severe early childhood caries (S-ECC) is an aggressive form of tooth caries in preschool children. New different bacteria were defined as associated with S-ECC. The aim of this study was to analysis the role of Scardovia wiggsiae and the other cariogenic microorganisms in S-ECC in Turkish children.

Methods: Two same-sized groups of children were enrolled in the study: the first group consisted of 40 children with S-ECC (meanage:52.93 \pm 11.5 months), and the second group consisted of 40 caries-free children (mean-age: $49.43 \pm 12.47$ months). The numbers of mutans streptococci, lactobacilli and yeasts were examined by culturing techniques, while the presences of $S$. wiggsiae, Streptococcus mutans, Streptococcus sobrinus, Actinomyces gerencseriae, Veillonella parvula, Fusobacterium nucleatum were examined by using $16 \mathrm{~S}$ rRNA-based PCR technique in plaque samples.

Results: The prevalence of S. wiggsiae, S. mutans, A. gerencseriae, V. parvula and the numbers of mutans streptococci, lactobacilli, yeasts were found significantly high $(\mathrm{P}<0.05)$ in SECC. Also, the presence of S. wiggsiae with either S. mutans, A. gerencseriae, V. parvula or F. nucleatum were associated $(\mathrm{P}<0.01)$ with S-ECC.
\end{abstract}

Conlusion: Findings of this study have demonstrated that S. wiggsiae, S. mutans, A. gerencseriae, V. parvula, mutans streptococci, lactobacilli and yeasts are strongly associated with S-ECC.

Clinical Relevance: Understanding the effects of bacteria on initiation and progression of S-ECC will also help to improve protective and preventive treatments.

Keywords: Severe early childhood caries; Scardovia wiggsiae; Streptococcus mutans; PCR

\section{Introduction}

Severe Early childhood caries (S-ECC) is a particularly aggressive form of dental caries affecting primary teeth of infants and preschool children and which affected by mainly complex biofilm microorganisms, fermentable carbohydrates, the saliva content, fluoride intake levels, oral hygiene, dietary habits and the socioeconomic and educational level of families [1].

S-ECC does not only affect teeth, also the results of this disease can increase of hospital and emergency service visits, and accordingly treatment expenses have also increased. Children's quality of life has decreased due to the problems in oral health. Moreover, cooperation problems of children affected by S-ECC necessitate complicated and expensive treatment options with general anesthesia or sedation $[1,2]$.

Developments in molecular studies using new technological opportunities, it has been shown that complex bacterial populations are effective in the progress of dental caries [3,4], S.mutans, Veillonella, Actinomyces, Bifidobacterium and Lactobacillus species have been found to be associated with S-ECC $[5,6]$. Kanasi et al. reported that S. mutans and Bifidobacterium species are in a strong relationship with S-ECC [7]. Kaur et al. found that high levels of salivary bifidobacteria are also associated with the increased number of caries activity in children [8]. Tanner et al. identified a highly significant relationship between the S-ECC and S. mutans, Scardovia wiggsiae, Veillonella parvula, Streptococcus cristatus, Fusobacterium nucleatum and Actinomyces gerencseriae 
[9]. In addition, the highly significant association of $S$. wiggsiae, which has been reported in the presence or absence of $S$. mutans, with the S-ECC [9].

The purpose of this study was to compare the S. wiggsiae and other caries-associated bacteria in children with S-ECC to those found in caries-free children by using culture method and 16S rRNA-based PCR in Turkish children in Istanbul.

\section{Materials and Methods}

\section{Study population}

Eighty children aged 24-66 months who have attended to Department of Pediatric Dentistry Clinics, Istanbul University Faculty of Dentistry, were enrolled in this study. The study period was determined as 1 year. Inclusion criteria of children were; medically healthy children, having a full primary dentition, and had not used antibiotics within the preceding 4 weeks. Forty children with S-ECC and 40 caries-free (CF) children with no caries (including white-spot) lesions or restorations were assessed for the study. Informed consent was obtained from each parent or guardian; and the study procedures were approved by Local Ethics Committee of the Istanbul University Faculty of Medicine (2013/1822).

\section{Clinical examination and microbiological sampling}

Decayed, missing, filled primary teeth and surfaces ( $\mathrm{dmft}, \mathrm{dmfs}$ ) were assessed according to WHO criteria [10]. Plaque Index (PI) [11] and Modified Gingival Index (MGI) (non-invasive/no probing technique) [12] were determined by only one examiner. Dental plaque was collected with a sterile toothbrush for $1 \mathrm{~min}$ from all sides of primary teeth of children in the study and control groups [13] by the same person. The brushes were transferred into sterile polystyrene tubes with $2 \mathrm{~mL}$ sterile saline solution and vortexed for 20 seconds for removing the adhered plaque. Thereafter, the plaque samples were divided into two; $1 \mathrm{~mL}$ for PCR analysis and stored at $-20^{\circ} \mathrm{C}$ before the extraction of genomic DNA and $1 \mathrm{~mL}$ for culturing immediately.

\section{Microbiological analysis of plaque samples}

Numbers of mutans streptococci (MS), lactobacilli (LB), yeasts were examined by selective culture method; and 16S rRNA-based PCR technique was performed for the detection of S. wiggsiae, S. mutans, S. sobrinus, A. gerencseriae, V. parvula and F. nucleatum.

Culture analysis: The samples were 10 -fold serially diluted and aliquots of $0.1 \mathrm{~mL}$ were plated on Mitis Salivarius Bacitracin agar (MSB) (Acumedia Man Inc., Baltimore, Maryland) for MS; on Rogosa Agar (Merck, KgaE, Damstadt, Germany) for LB and on Sabouraud Dextrose Agar (Merck) for yeast counts. MSB Agar and Rogosa Agar plates were incubated in air supplemented with 5-7 \% $\mathrm{CO}_{2}$, while Sabouroud Dextrose Agar plates were incubated aerobically. After $48 \mathrm{~h}$ incubation at $37^{\circ} \mathrm{C}$, the typical colonies were enumerated and calculated as $\mathrm{cfu} / \mathrm{mL}$. A high level was considered to be $\geq 10^{5} \mathrm{cfu} / \mathrm{mL}$ for $\mathrm{MS}, \geq 10^{4} \mathrm{cfu} / \mathrm{mL}$ for LB and $\geq 10^{2}$ $\mathrm{cfu} / \mathrm{mL}$ for yeasts; which detection limits were $10^{3}, 10^{2}$ and $10 \mathrm{cfu} / \mathrm{ml}$ respectively [14].

PCR analysis: DNA was isolated from the plaque samples, by using a High Pure PCR Template Preparation Kits (Roche, Mannheim, Germany) as recommended by the manufacturer.

S. mutans (ATCC 25175), S. sobrinus (ATCC 33478), F. nucleatum (ATCC 25586), V. parvula (ATCC 10790) were obtained from the American Type Culture Collection (Rockville, MD), and S. wiggsiae (DSM 22547) and A. gerencseriae (DSM 6844) were obtained from the Leibniz Institut DSMZ - German Collection of Microorganisms and Cell Cultures. These freeze dried form of bacteria were also extracted to serve as positive control for the species specific primer used or to evaluate the specificity of the primer while sterile distilled water was used as a negative control for each reaction series. Species specific primers and amplication protocols [2,15-18] were showed in Table 1.

\begin{tabular}{|c|c|c|c|c|}
\hline Bacteria & Universal primers (5'- 3') & AL & AC & References \\
\hline S. wiggsiae & $\begin{array}{l}\text { GTGGACTTTATGAATAAGC } \\
\text { CTACCGTTAAGCAGTAAG }\end{array}$ & $172 \mathrm{bp}$ & $\begin{array}{l}40 \text { cycles: } \\
94^{\circ} \mathrm{C} 20 \text { s } \\
51^{\circ} \mathrm{C} 20 \text { s } \\
72^{\circ} \mathrm{C} 20 \mathrm{~s}\end{array}$ & $\begin{array}{c}\text { Tanner et al. } \\
2011 \text { [2] }\end{array}$ \\
\hline S.mutans & $\begin{array}{c}\text { GGTCAGGAAAGTCTGGAGTAAAAGGCTA } \\
\text { GCGGTAGCTCCGGCACTAAGCC }\end{array}$ & $282 \mathrm{bp}$ & $\begin{array}{l}36 \text { cycles: } \\
95^{\circ} \mathrm{C} 45 \mathrm{~s} \\
55^{\circ} \mathrm{C} 30 \mathrm{~s} \\
72^{\circ} \mathrm{C} 45 \mathrm{~s}\end{array}$ & $\begin{array}{l}\text { Corpet } 1988 \\
\text { [15] }\end{array}$ \\
\hline S.sobrinus & $\begin{array}{l}\text { CGGACTTGCTCCAGTGTTACTAA } \\
\text { GCCTTTAACTTCAGACTTAC }\end{array}$ & $546 \mathrm{bp}$ & $\begin{array}{l}36 \text { cycles: } \\
95^{\circ} \mathrm{C} 45 \mathrm{~s} \\
55^{\circ} \mathrm{C} 30 \mathrm{~s} \\
72^{\circ} \mathrm{C} 45 \mathrm{~s}\end{array}$ & $\begin{array}{l}\text { Corpet } 1988 \\
\text { [15] }\end{array}$ \\
\hline A. gerencseriae & $\begin{array}{l}\text { TCACTTCTGGATAACCGCTT } \\
\text { CAAACAGTGCCATCTTTCCCGA }\end{array}$ & $90 b p$ & $\begin{array}{l}30 \text { cycles: } \\
94^{\circ} \mathrm{C} 20 \mathrm{~s} \\
53^{\circ} \mathrm{C} 30 \mathrm{~s} \\
60^{\circ} \mathrm{C} 40 \mathrm{~s}\end{array}$ & $\begin{array}{l}\text { Yang et al. } \\
2007[16]\end{array}$ \\
\hline
\end{tabular}




\begin{tabular}{|c|c|c|c|c|}
\hline Bacteria & Universal primers ( $\left.5^{\prime}-3^{\prime}\right)$ & AL & $\mathrm{AC}$ & References \\
\hline V. parvula & $\begin{array}{l}\text { GAAGCATTGGAAGCGAAAGTTTCG } \\
\text { GTGTAACAAGGGAGTACGGACC }\end{array}$ & $623 \mathrm{bp}$ & $\begin{array}{l}20 \text { cycles: } \\
92^{\circ} \mathrm{C} 60 \mathrm{~s} \\
57^{\circ} \mathrm{C} 60 \mathrm{~s} \\
72^{\circ} \mathrm{C} 60 \mathrm{~s}\end{array}$ & $\begin{array}{l}\text { Igarashi et al. } \\
2009[17]\end{array}$ \\
\hline F. nucleatum & $\begin{array}{l}\text { AGA GTT TGA TCC TGG CTC AG } \\
\text { GTC ATC GTG CAC ACA GAA TTG CTG }\end{array}$ & $360 \mathrm{bp}$ & $\begin{array}{l}36 \text { cycles: } \\
94^{\circ} \mathrm{C} 45 \mathrm{~s} \\
55^{\circ} \mathrm{C} 30 \mathrm{~s} \\
72^{\circ} \mathrm{C} 45 \mathrm{~s}\end{array}$ & $\begin{array}{l}\text { Conrads et al. } \\
1997[18]\end{array}$ \\
\hline \multicolumn{5}{|c|}{ AL: Amplication Lenght, AD: Amplication Cycles, bp: baz pair, s: second } \\
\hline
\end{tabular}

Following amplification, $10 \mu \mathrm{l}$ of PCR products were analyzed by using 1\% agarose gel electrophoresis [9]. Gels were stained with $0.5 \mu \mathrm{g}$ ethidium bromide and visualized by ultraviolet light illumination. A 100-bp DNA ladder digest (Biotools) served as the molecular size standard.

To confirm the specificity of the primers, randomly selected representative amplicons of samples from the $S$. wiggsiae primers were sequenced and analyzed using the BLAST algorithm (https://blast.ncbi.nlm.nih.gov/Blast.cgi). The samples showed 100\% similarity to S. wiggsiae F0424 cont1.1 (Accession number: NZ_AKCI01000001.1; Request ID: ZVZYB8G6014 ).

\section{Statistical analysis}

The analysis were performed with the IBM SPSS Statistics 22 (IBM SPSS, TURKEY) software. Student's t test and Continuity (yates) correction was used for the analysis of groups according to age and gender $(\mathrm{p}>0.05)$. Mann Whitney $U$ test was used to compare the both groups, the plaque index and modified gingival index value $(\mathrm{P}<0.01)$. Chi-square test was used for culture analysis data in groups. Fisher's Exact test and/or Continuity (yates) correction was used for assessment of the prevalence of microorganisms by PCR analysis and the association of S. wiggsiae with S. mutans, A. gerencseriae, V. parvula or F. nucleatum.

\section{Results}

\section{Demographic and Clinical Characteristics of Study Population}

The study population comprised 40 S-ECC (16girls and 24boys) and 40 caries-free (CF) (22girls and 18boys) children with mean ages of $52.93 \pm 11.5$ months and $49.43 \pm 12.47$ months, respectively. There were no significant age and gender difference between $\mathrm{S}-\mathrm{ECC}$ and CF children $(\mathrm{P}>0.05)$.

The mean dft and dfs in S-ECC group were determined as $13,85 \pm 3,43$ and $28.55 \pm 11.94$, respectively. The mean plaque index (PI) and modified gingival index (MGI) in S-ECC group were determined as $0.79 \pm 0.45$ and $0.42 \pm 0.50$, in CF group were determined as $0.15 \pm 0.21$ and $0.01 \pm 0.05$ respectively. The SECC group had a significantly higher mean plaque index and modified gingival index score than CF group $(\mathrm{P}<0.01)$.

\section{Microbiological results}

Frequencies of mutans streptococci (MS), lactobacilli (LB) and yeasts are presented in Table 2. Significantly high levels of MS (80\% , $\mathrm{n}=32), \mathrm{LB}(42.5 \%, \mathrm{n}=17)$ and yeast $(37.5 \%, \mathrm{n}=15)$ were found in SECC group than CF group.

\begin{tabular}{|c|c|c|c|c|}
\hline & & S-ECC & CF & \\
\hline & & n (\%) & n (\%) & \\
\hline \multirow{3}{*}{ MS } & low & $3(7.5 \%)$ & $7(17.5 \%)$ & \multirow{3}{*}{$0.034^{\star}$} \\
\hline & medium & $5(12.5 \%)$ & $12(30 \%)$ & \\
\hline & high & $32(80 \%)$ & $21(52.5 \%)$ & \\
\hline \multirow{3}{*}{ LB } & low & $6(15 \%)$ & $29(72.5 \%)$ & \multirow{3}{*}{$0.001^{\star *}$} \\
\hline & medium & $17(42.5 \%)$ & $5(12.5 \%)$ & \\
\hline & high & $17(42.5 \%)$ & $6(15 \%)$ & \\
\hline \multirow{3}{*}{ Yeast } & low & $9(22.5 \%)$ & $32(80 \%)$ & \multirow{3}{*}{$0.001^{\star \star}$} \\
\hline & medium & $16(40 \%)$ & $6(15 \%)$ & \\
\hline & high & $15(37.5 \%)$ & $2(5 \%)$ & \\
\hline
\end{tabular}

Assessment of the prevalence of microorganisms in the groups by PCR analysis is shown in Figure 1. 


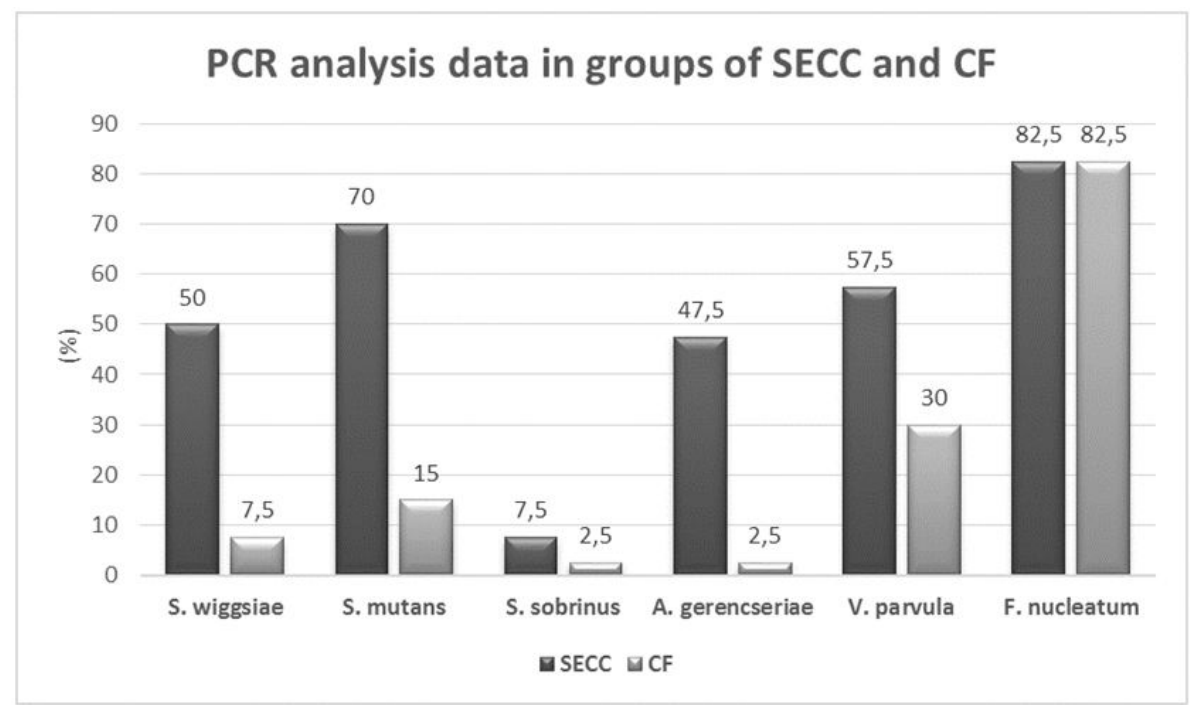

Figure 1: Assessment of the prevalence of microorganisms in the groups by PCR analysis

S. wiggsiae, S. mutans, A. gerencseriae and V. parvula prevalences in SECC group was found significantly higher than control group. Statistically significant difference was not found between the prevalences of $S$. sobrinus and that of F. nucleatum with the two groups $(\mathrm{P}>0.05)$.

The prevalence of $S$. wiggsiae in SECC group in absence of $S$. mutans was determined higher than the control group, however no significance was found between the groups $(\mathrm{P}>0.05)$.

The association of S. wiggsiae combination with S. mutans, A. gerencseriae, V. parvula or F. nucleatum in SECC group was presented in Table 3.

\begin{tabular}{|c|c|c|c|}
\hline & SECC & CF & \multirow{2}{*}{ P } \\
\cline { 2 - 3 } & $\mathbf{n}(\%)$ & $\mathbf{n}(\%)$ & \\
\hline Sw+Ag & $11(27.5 \%)$ & - & \multirow{2}{*}{$\mathbf{0 . 0 0 1}^{\text {** }}$} \\
\hline Sw+Vp & $14(35 \%)$ & $1(2.5 \%)$ & $\mathbf{0 . 0 0 1}^{\text {** }}$ \\
\hline Sw+Fn & $16(40 \%)$ & $2(5 \%)$ & $\mathbf{0 . 0 0 1}^{\text {** }}$ \\
\hline Sw+Sm & $16(40 \%)$ & - & $\mathbf{0 . 0 0 1}^{\text {** }}$ \\
\hline Sw+Sm+Fn+Vp+Ag & $6(15 \%)$ & - & $\mathbf{0 . 0 0 1}^{\text {** }}$ \\
\hline Sw+Fn+Vp & $12(30 \%)$ & - & $\mathbf{0 . 0 0 1}^{\text {** }}$ \\
\hline
\end{tabular}

Fisher's Exact test ve/veya Continuity (yates) correction ${ }^{* *} P<0.01$

Table 3: The association of S.wiggsiae with S.mutans, A.gerencseriae, V.Parvula or F.nucleatum

The presence of S. wiggsiae and A. gerencseriae, S. wiggsiae and V parvula, S. wiggsiae and F. nucleatum, and S. wiggsiae and S. mutans were found significantly higher in SECC group than control group (P:0.001; $\mathrm{P}<0.01)$. The assemblages of $S$. wiggsiae, $S$. mutans, A. gerencseriae, V parvula and F. nucleatum are 15\%; S. wiggsiae, F. nucleatum, V. parvula are 30\% in SECC group

\section{Discussion}

In studies examining SECC microbiota, the saliva and plaque samples taken from children have been analyzed. It has been stated that the samples could be taken by using various tools such as sterile cotton tip, periodontal curette, dental explorer, wooden toothpicks, and endodontic paper point $[5,9,19,20]$. In this study, sterile toothbrush was utilized, as recommended by Okada et al. 13. In method of plaque collection via toothbrush, the consent of the parents can be achieved easily, and rapid and secure collection of the samples can be ensured without leading children to have any fear.

It is known that dental plaque microorganisms are closely related with SECC [21]. For understanding caries microbiota, beside the traditional microbiological methods such as cultivation and light microscopy, the molecular genetic analysis have created a new revolution in determining of special species in cariogenic microbiota. It is emphasized that the complex bacteria communities playing role in tooth caries could be clarified by the new molecular diagnosis methods utilized in examination of oral microbiota $[3,6,7,22]$. In this study, beside the traditional cultivation methods, the PCR analysis by utilizing species-specific 16 SrRNA primers for determination of selected microorganisms has been used.

According to the cultivation analysis in this study, the numbers of MS, LB and yeasts in plaque samples from children having 
SECC have been determined to be significantly higher than those of CF-children. This finding is in accordance with the results of Bolgul et al. [23] , who investigated the levels of MS, LB and yeast are effective in formation and progression of caries in preschool children in Turkey. Also Klinke (2014) [24] and Jose (2014) [25] et al. showed that there was a strong association between SECC and MS, LB, yeast levels.

The recent studies have shown that there are many different species in dental plaque, and that they have a role in formation and development of caries by producing acid from dietary carbohydrates $[6,19,25]$.

S. wiggsiae, which is a member of Bifidobacteriaceae family, is recently identified and thought to be an important part of cariesrelated microbial complex [9]. Studies have showed that there is a relationship between the presence of caries and Bifidobacteriaceae Bifidobacteria and Scardovia's high prevalence [7,8,26,27].

Researchers reported that S. mutans, S. wiggsiae, V. parvula, S. cristatus, F. nucleatum and A. gerencseriae are SECC-related species [28], and S. wiggsiae is effective in childhood caries both in presence and absence of S. mutans [9]. Moreover, since S. wiggsiae is highly isolated in white spot lesions and at the initiation of enamel lesions, it is thought to be efficient in initiation of caries, as well as S. mutans [29]. Vacharaksa et al. reported a higher prevalence and abundance of S. wiggsiae in infected dentine and dental plaque of children with ECC compared to caries-free children, which emphasises the role of this bacterium in caries development and progression [22]. In this study, it has been determined that S. wiggsiae, S. mutans, A. gerencseriae and V. parvula prevalence in S-ECC group was significantly higher than control group, and the prevalence of $S$. wiggsiae in S-ECC group in absence of $S$. mutans was higher than control group, but the difference was not significant.

In another study of Tanner et al, on children having S-ECC via species-specific PCR, it has been determined that $S$. mutans, S. sobrinus, Bifidobacteriaceae, S. wiggsiae alone and the combinations of S. sobrinus with S. mutans, Bifidobacteriaceae with S. mutans, and S. wiggsiae with S. mutans have been found to be related with S-ECC [2]. Vacharaksa et al. have showed that $S$. wiggsiae in combination with $S$. mutans is better for caries risk assessment in children [22]. In this study, it has been determined that the assemblages of S. wiggsiae, S. mutans, A. gerencseriae, V parvula and F. nucleatum, the combinations of $S$. wiggsiae and A. gerencseriae, S. wiggsiae and V. parvula, S. wiggsiae and F. nucleatum, and S. wiggsiae and S. mutans were significantly higher in S-ECC group. It is also striking to see a high rate (40\%) association between S. wiggsiae and S. mutans in S-ECC group. Although S. mutans is considered as primary pathogen for caries and exists also in CF individuals, S. wiggsiae isolated even in some of S-ECC cases where $S$. mutans was not detected suggests that this new pathogen might be independently related with caries. Another thought is that $S$. mutans is not a dominant species in caries microbiota as it is stated and S. wiggsiae could be a secondary occupant and related with progression of caries into the dentin in further stages of the infection [9]. However, there are limited number of studies on S. wiggsiae, and in which stage of caries formation and progression it is active has not been clearly revealed. Besides, further studies are needed for acquisition and transmission of S. wiggsiae and also for detection of it in predentate period, mix and permanent dentitions.

Aas et al. have determined Fusobacterium species at high levels in both of healthy oral cavity and early-phase caries lesions [6]; and Tanner et al. have reported significant relationship between F. nucleatum and S-ECC [9]. Hughes et al. (cultivation method) and Palmer et al. (PCR method) have found high level of relationship between S. sobrinus and S-ECC [20,26]. In this study, MSs have been found at high level in the children having S-ECC by using cultivation technique, but S. sobrinus has been detected at low levels in both of no-caries and S-ECC groups by using species-specific PCR method. In S-ECC and no-caries groups, no statistically significant difference could be found between the prevalence of S. sobrinus and that of F. nucleatum; and F. nucleatum has been observed in both of S-ECC and no-caries groups at 80\% levels. High level of F. nucleatum detected in both of two groups suggests that it may be related to a permanent member of the natural microbiota.

The population of children in this study was limited to only 80 patients in Istanbul, Turkey. There is need for research to be carried out in different regions and in the wider participants for understanding caries microbiata in S-ECC. Also S. wiggsiae and A. gerencseriae are important in terms of the investigation for the first time in Turkish children.

The studies have shown that there is not only single pathogen that is responsible for caries, but the pathogenic population in dental plaque could be effective for the development and progression of caries. In caries microbiome studies, various bacteria species related with caries have been identified at different levels. Since ecological balance of each mouth is different, different results have been achieved in the studies. However, in general, especially S. mutans, LB, Actinomyces, and Veillonella and S. wiggsiae have been found to be relevant with the early childhood caries, further studies are needed for better understanding the role of microbiota in caries etiology.

\section{Conclusion}

1. The frequency of detection of MS, LB, yeasts, S. wiggsiae, S. mutans, A. gerencseriae and V. parvula were found significantly greater in the S-ECC.

2. The combinations of S. wiggsiae with S. mutans, A. gerencseriae, V. parvula and F. nucleatum were associated with S-ECC $(P<0.01)$. 


\section{Acknowledgment}

This study was supported by the Research Fund of Istanbul University (Project no. 40373). All authors have made substantive contributions to this study and the manuscript and all have reviewed the final paper prior to its submission.

\section{References}

1. American Academy of Pediatric Dentistry, American Academy of Pediatrics (2008-2009) Policy on early childhood caries (ECC): classifications, consequences, and preventive strategies. Pediatr Dent 30: 40-3.

2. Tanner AC, Kent RL, Holgerson PL, Hughes CV, Loo CY, et al. (2011) Microbiota of severe early childhood caries before and after therapy. J Dent Res 90: 1298-305.

3. Wade WG (2013) The oral microbiome in health and disease. Pharmacol Res 69: 137-43.

4. Jagathrakshakan SN, Sethumadhava RJ, Mehta DT, Ramanathan A (2015) 16 S rRNA gene-based metagenomic analysis identifies a novel bacterial co-prevalence pattern in dental caries. Eur J Dent 9: 127-32.

5. Becker MR, Paster BJ, Leys EJ, Moeschberger ML, Kenyon SG, et al. (2002) Molecular analysis of bacterial species associated with childhood caries. J ClinMicrobiol 40: 1001-9.

6. Aas JA, Griffen AL, Dardis SR, Lee AM, Olsen I, et al.(2008) Bacteria of dental caries in primary and permanent teeth in children and young adults. J Clin Microbiol 46: 1407-17.

7. Kanasi E, Dewhirst FE, Chalmers NI, Kent R, Moore A, et al. (2010) Clonal analysis of the microbiota of severe early childhood caries. Caries Res 44: 485-97.

8. Kaur R, Gilbert SC, Sheehy EC, Beighton D (2013) Salivary levels of Bifidobacteria in caries-free and caries-active children. Int J Paediatr Dent 23: $32-8$.

9. Tanner AC, Mathney JM, Kent RL, Chalmers NI, Hughes CV, et al. (2011) Cultivable anaerobic microbiota of severe early childhood caries. J Clin Microbiol 49: 1464-74.

10. World Health Organization (1997) Oral health surveys - basic methods, (4 $4^{\text {th }}$ Edn) Geneva, Switzerland.

11. Silness J, Löe H (1964) Periodontal disease in pregnancy II. Correlation between oral hygiene and periodontal condition. Acta Odontol Scand 22: 121-35.

12. Lobene RR, Weatherford T, Ross NM, Lamm RA, Menaker L (1986) modified gingival index for use in clinical trials. Clin Prev Dent 8: 3-6.

13. Okada M, Hayashi F, Nagasaka N (2000) Detection of Actinobacillus actinomycetemcomitans and Porphyromonas gingivalis in dental plaque samples from children 2 to 12 years of age. J Clin Periodontol 27: 763-8.

14. Topcuoglu N, Balkanlı O, Yaylalı D, Külekçi G (2012) The effects of the tuft design and toothpaste on the residual microbial contamination of toothbrushes. Turk Hij Den Biyol Derg 69: 219-24.

15. Corpet F (1988) Multiple sequence alignment with hierarchical clustering. Nucleic Acids Res 16: 10881-90.

16. Yang R, Zou J, Li JY (2007) Study of the relationship between oral Actinomyces and childhood caries. Hua Xi Kou Qiang Yi Xue Za Zhi 25: 568-70.

17. Igarashi E, Kamaguchi A, Fujita M, Miyakawa H, Nakazawa F (2009) Identification of oral species of the genus Veillonella by polymerase chain reaction. Oral Microbiol Immunol 24: 310-3.

18. Conrads G, Gharbia SE, Gulabivala K, Lampert F, Shah H (1997) The use of a 16s rDNA directed PCR for the detection of endodontopathogenic bacteria. J Endod 23: 433-8.

19. Gross EL, Beall CJ, Kutsch SR, Firestone ND, Leys EJ, et al. (2012) Beyond Streptococcus mutans: dental caries onset linked to multiple species by $16 \mathrm{~S}$ rRNA community analysis. PLoS One 7: e47722.

20. Hughes CV, Dahlan M, Papadopolou E, Loo CY, Pradhan NS, et al. (2012) Aciduric microbiota and mutans streptococci in severe and recurrent severe early childhood caries. Pediatr Dent 4: 16-23.

21. Jiang W, Zhang J, Chen H (2013) Pyrosequencing analysis of oral microbiota in children with severe early childhood dental caries. Curr Microbiol 67: 537-42. 22. Vacharaksa A, Suvansopee P, Opaswanich N, Sukarawan, W (2015) PCR detection of Scardovia wiggsiae in combination with Streptococcus mutans for early childhood caries-risk prediction. Eur J Oral Sci 123:312-8.

23. Bolgul BS, Celenk S, Buket EA, Atakul F (2004) Associations of Dental Caries with Salivary Mutans Streptococci/Lactobacilli and Plaque pH in 7-9 Years Old Children in Rural of Diyarbakır-Turkey. Turkiye Klinikleri J Dental Sci 10: 69-73.

24. Klinke T, Urban M, Lück C, Hannig C, Kuhn M, et al. (2014) Changes in Candida spp., mutans streptococci and lactobacilli following treatment of early childhood caries: a 1-year follow-up. Caries Res 48: 24-31.

25. Jose T, Thomas A, Pidamale R, Mhambrey S, Shetty SB (2014) Correlation between C. albicans, S. mutans, S. sanguinis and Lactobacillus in ECC, SECC and caries free. Int J of Recent Sci Res 5: 352-6.

26. Palmer CA, Kent R, Loo CY, Hughes CV, Stutius E, et al. (2010) Diet and caries-associated bacteria in severe early childhood caries. J Dent Res 89: 1224-9.

27. Mantzourani M, Gilbert SC, Sulong HN, Sheehy EC, Tank S, et al. (2009) The isolation of bifidobacteria from occlusal carious lesions in children and adults. Caries Res 43: 308-13.

28. Tanner AC, Sonis AL, Lif Holgerson P, Starr JR, Nunez Y, et al. (2012) White-spot lesions and gingivitis microbiotas in orthodontic patients. J Dent Res 91: 853-8.

29. Torlakovic L, Klepac-Ceraj V, Ogaard B, Cotton SL, Paster BJ, et al. (2012) Microbial community succession on developing lesions on human enamel. J Oral Microbiol doi: 10.3402/jom.v4i0.16125. 


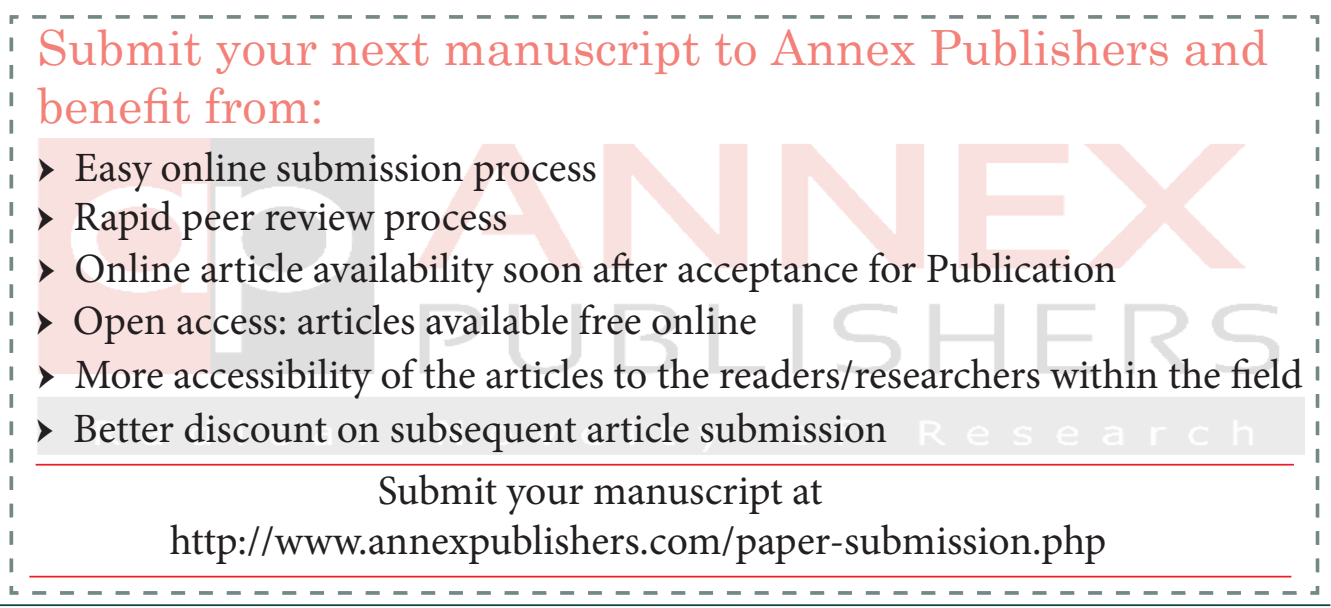

